\begin{tabular}{|c|l|}
\hline Title & Synthesis of pacidamycin anal ogues via an Ugi-multicomponent reaction \\
\hline Author(s) & $\begin{array}{l}\text { Okamoto, Kazuya; Sakagami, Masahiro; Feng, Fei; Takahashi, Fumiyo; Uotani, Kouichi; Togame, Hiroko; Takemoto, } \\
\text { Hiroshi; IChikawa, Satoshi; Matsuda, A kira }\end{array}$ \\
\hline Citation & $\begin{array}{l}\text { BIOORGA NIC \& MEDICINAL CHEMISTRY LETTERS, 22(14), 4810-4815 } \\
\text { https:/doi.org/L0.1016/.bmcl.2012.05.050 }\end{array}$ \\
\hline Issue Date & 2012-07-15 \\
\hline Doc URL & http://hdl.handle.net/2115/54870 \\
\hline Type & article(author version) \\
\hline File Information & Matsuda_A kira_2012_Bioorg_Med_Chem_Lett.pdf \\
\hline
\end{tabular}

Instructions for use 


\title{
Synthesis of Pacidamycin Analogues via an Ugi-Multicomponent Reaction
}

\author{
Kazuya Okamoto, ${ }^{\mathrm{a}}$ Masahiro Sakagami, ${ }^{\mathrm{a}}$ Fei Feng, ${ }^{\mathrm{b}}$ Fumiyo Takahashi, \\ Kouichi Uotani, ${ }^{\mathrm{c}}$ Hiroko Togame, ${ }^{\mathrm{a}}$ Hiroshi Takemoto, ${ }^{\mathrm{a}}$ Satoshi \\ Ichikawa, $^{\mathrm{d}, *}$ Akira Matsuda ${ }^{\mathrm{d}}$
}

\begin{abstract}
${ }^{a}$ Shionogi Innovation Center for Drug Discovery, Shionogi \& Co., Ltd., Kita-21 Nishi-11, Kita-ku, Sapporo 001-0021, b Faculty of Advanced Life Science, Hokkaido University, Kita-21, Nishi-11, Kita-ku, Sapporo, 001-0021, ${ }^{\mathrm{c}}$ Medicinal Research Laboratories, Shionogi \& Co., Ltd., 3-1-1, Futaba-cho, Toyonaka, Osaka 561-0825, ${ }^{\mathrm{d}}$ Faculty of Pharmaceutical Sciences, Hokkaido University, Kita-12, Nishi-6, Kita-ku, Sapporo 060-0812, Japan
\end{abstract}

*Corresponding author: Satoshi Ichikawa

Tel (+81)11-706-3229

Fax (+81)11-706-4980

e-mail: ichikawa@pharm.hokudai.ac.jp 


\section{Abbreviations}

$\alpha, \beta$-diaminobutylic

acid

(DABA),

2-(1H-7-azabenzotriazol-1-yl)-1,1,3,3-tetramethyluronium

hexafluorophosphate

(HATU), phospho-MurNAc-pentapeptide transferase (MraY), N-methylmorpholine (NMM), structure-activity relationship (SAR), Ugi-four component reaction (U-4CR) 


\begin{abstract}
The second-generation synthesis of 3'-hydroxypacidamycin D (2) has been accomplished via an Ugi-four component reaction at a late stage of the synthesis. This approach provided ready access to a range of analogues including diastereomers of the diaminobutylic acid residue and hybrid-type analogues of mureidomycins. Biological evaluations of these analogues indicated that the stereochemistry at the diaminobutylic acid residue has a crucial impact on both the MraY biochemical inhibition and whole-cell antibacterial activity.
\end{abstract}


The pacidamycins (Figure 1, 1), ${ }^{1}$ first isolated from Streptomyces coeruleorubidus $\mathrm{AB} 1183 \mathrm{~F}-64$ in 1989 , are members of a class of uridylpeptide antibiotics, ${ }^{2}$ that are composed of the mureidomycins, ${ }^{3}$ the napsamycins, ${ }^{4}$ and the recently identified sansanmycins. ${ }^{5}$ Sharing a characteristic structural feature, namely a $3^{\prime}$-deoxyuridine which is attached to a tetrapeptide moiety by an enamide linkage. These compounds exhibit selective antibacterial activity against Pseudomonas aeruginosa, a common nosocomial pathogen that is intrinsically resistant to a variety of drugs currently used in the clinic. Consequently, immuno-compromised patients are at greater risk of infection. Moreover, the increased rate of acquired multidrug resistance in $P$. aeruginosa complicates anti-Pseudomonas chemotherapy, thereby making the development of novel antibacterial agents that are active against multi-drug resistance $P$. aeruginosa all the more urgent. ${ }^{6-8}$ These uridylpeptide antibiotics are sub-nanomolar inhibitors of their biological target, the phospho-MurNAc-pentapeptide transferase (MraY), ${ }^{2,9}$ which is responsible for the formation of lipid I in the peptidoglycan biosynthesis pathway., ${ }^{2,10}$ Inhibition of the MraY by these antibiotics causes a malfunction of the peptidoglycan production in a manner different from $\beta$-lactams such as the carbapenems. Since MraY is an essential enzyme in bacteria ${ }^{2}$ and a novel target, uridylpeptide antibiotics are expected to be highly useful anti-Pseudomonal agents. Intrigued by the promising 
biological activity, several groups have conducted structure-activity relationship studies. ${ }^{11-15}$

We have recently accomplished the total synthesis of pacidamycin D (1) and its 3'-hydroxyl analogue 2 , which features a stereoselective construction of the Z-oxy-acyl enamide architecture by a copper-catalyzed $\mathrm{C}-\mathrm{N}$ cross-coupling. ${ }^{16}$ These compounds exhibited strong MraY inhibitory activity $\left(\mathrm{IC}_{50}=22 \mathrm{nM}\right.$ for $\mathbf{1}, 42 \mathrm{nM}$ for 2$)$ and potent antibacterial activity against $P$. aeruginosa (MIC 8-64 $\mu \mathrm{g} / \mathrm{mL}$ ). The existence of the hydroxyl group at the 3'-position of the uridine moiety does not have any impact on either MraY inhibition or antibacterial activity. This first generation strategy, however, is a linear synthesis, where the vinyl iodide derivative of uridine was coupled with the tetrapeptide carboxamide moiety. Nonetheless, from a medicinal point of view, the development of a convergent synthetic strategy that would provide analogues more efficiently is preferable. A multi-component reaction would be ideally suited for structure-activity relationship (SAR) studies since it allows for diversification of accessible analogs simply by altering each component. We have successfully applied an Ugi-four component reaction (U-4CR) in pursuing the SAR of the muraymycins, which are antibacterial nucleoside natural products. ${ }^{17}$ Herein we describe the second-generation synthesis of 2 via a U-4CR in order to establish a convergent 
synthetic strategy appropriate for the SAR study of uridylpeptide antibiotics. The biological evaluation of several analogues is also described.

Our second-generation retrosynthetic analysis of 2 is summarized in Scheme 1. We planned to install the $N$-terminal amino acid residue 3 on $\mathbf{4}$ in the final stage of the synthesis considering the initial efforts to prepare $\mathbf{2}$ as described later. We retrosynthetically divided 4 into the urea dipeptide 5, 2,4-dimethoxybenzylamine 6, the 2- $N$-methylaminopropionaldehyde derivative 7 , and the $\alpha, \beta$-unsaturated isonitrile derivative of uridine 8 for the U-4CR. This strategy allowed us to construct 4 with the non-proteinogenic amino acid $\alpha, \beta$-diaminobutylic acid (DABA) residue, with linkages to the urea dipeptide and uridine moieties at the $C$ - and $N$-termini. Moreover, the U-4CR strategy has the advantage of efficiently furnishing diastereomers that are useful for the SAR. Considering the nature of the multi-component assemblage, this strategy allows easy access to diversified analogues.

The aldehyde unit 7 was prepared as shown in Scheme 2. Namely, $N$-formyl-L-alanine 9 was reduced by $\mathrm{LiAlH}_{4}$, and the resulting $\mathrm{N}$-methylaminoalcohol was selectively protected by a Boc group to provide $\mathbf{1 0}$ in $98 \%$ yield over 2 steps. The primary hydroxyl group of $\mathbf{1 0}$ was oxidized by Dess-Martin periodinane to give $\mathbf{7}$ in $84 \%$ yield. The isonitrile $\mathbf{8}$ was prepared from the Z-enamide 12 by the 
copper-catalyzed C-N cross-coupling of the Z-vinyl iodide $\mathbf{1 1}^{16}$ and formamide as describe in Scheme 3. The iodide 11 was reacted with formamide using 0.2 equiv. of CuI, 0.4 equiv. of $\mathrm{MeNHCH}_{2} \mathrm{CH}_{2} \mathrm{NHMe}, \mathrm{Cs}_{2} \mathrm{CO}_{3}$ in THF at $70{ }^{\circ} \mathrm{C}$ to give the desired Z-enamide 12, which was obtained selectively in $90 \%$ yield. The corresponding E-isomer was not observed at all during the course of the reaction. Dehydration of 12 was achieved by a treatment with triphosgene and $\mathrm{Et}_{3} \mathrm{~N}$ in $\mathrm{CH}_{2} \mathrm{Cl}_{2}$ at $-78{ }^{\circ} \mathrm{C}$ to provide the isonitrile 8 in $88 \%$ yield.

With 7 and 8 in hand, we then examined the assemblage of the four components by the U-4CR (Scheme 4). The assemblage proceeded simply by mixing 5, 6, 7, and 8 in EtOH at room temperature for $48 \mathrm{~h}$, and the desired $\mathbf{1 3}$ and its diastereomer at the newly formed stereogenic center were obtained in acceptable yields (33\% for $\mathbf{1 3}$ and $30 \%$ for 14). These were separated by silica gel column chromatography. Initially we planned to use an aldehyde of the dipeptide derivative such as $\mathbf{2 1}$, which was prepared by reduction of the Weinreb amide derivative of the dipeptide $\mathbf{2 0}$, as the aldehyde component in the U-4CR assemblage (Scheme 5). However, it turned out that the resulting aldehyde 21 easily cyclized to form a rather stable cyclic aminal 22, and the U-4CR did not proceed at all. Therefore we turned our attention to the stepwise synthetic route toward the target compounds as shown in Scheme 4 in order to avoid the undesired cyclization. 
The final assemblage of the remaining amino acid and global deprotection were then investigated. Upon selective removal of the Boc group of $\mathbf{1 3}\left(10 \% \mathrm{TFA}, \mathrm{CH}_{2} \mathrm{Cl}_{2}, 0{ }^{\circ} \mathrm{C}\right)$, the liberated secondary amine of $\mathbf{1 5}$ was condensed with $N$-Boc-L-Ala 3 (HATU, $N$-methylmorpholine (NMM), $\mathrm{CH}_{2} \mathrm{Cl}_{2}$ ) to give the fully protected 3'-hydroxyl pacidamycin D analogue 17 in 79\% yield over 2 steps. Finally removal of all the protecting groups $\left(\mathrm{BCl}_{3}, \mathrm{CH}_{2} \mathrm{Cl}_{2},-78{ }^{\circ} \mathrm{C}, 5 \mathrm{HF} \cdot \mathrm{NEt}_{3}, 22 \%\right.$ over 2 steps $)$ successfully afforded 2. The analytical data for $\mathbf{2}$ in this second generation synthesis were identical to those of the material previously synthesized. ${ }^{16 a}$ The deprotection step gave poor yield of the desired 2 because $\mathrm{BCl}_{3}$ treatment resulted in decomposition of the acid sensitive enamide moiety as well as migration of the 2,4-dimethoxy group to the indole moiety of the Trp residue. Similar problems were also observed for the formation of 19, 27, 30 , and 31, which were described later. The epimer at the DABA residue 19 was also prepared from $\mathbf{1 4}$ in a manner similar to that of the synthesis of $\mathbf{2}$.

The mureidomycins (Figure 2) ${ }^{3}$ were first isolated from Streptomyces flavidoviridens SANK 60486 and belong to the same class of uridylpeptide antibiotics. However, their amino acids differ from those of the pacidamycins. Mureidomycin $\mathrm{C}$, which has the dipeptide (Gly-L-m-Tyr) at the $N$-terminus, showed the most potent 
antibacterial activity against strains of $P$. aeruginosa among the uridylpeptide antibiotics with MICs ranging from 0.1 to $1.56 \mu \mathrm{g} / \mathrm{mL} .^{3 \mathrm{~b}}$

We therefore planned to prepare an analogue 27a, which is a hybrid-type of pacidamycin D and mureidomycin C, by introducing the Gly-L-m-Tyr moiety into the intermediates 15 and 16 (Scheme 6). The analogue 27b, where the L-m-Tyr residue at the $N$-terminus was replaced by L-Tyr, was designed in order to determine the consequences of placing of the hydroxyl group in this position. The glycine analogue 27c was also prepared. These analogues $27 \mathbf{a}-\mathbf{c}$, as well as $\mathbf{3 0}$, the epimer of $\mathbf{2 7}$ a at the DABA residue, were prepared by the same strategy as that for the synthesis of 2 and 19 by using the dipeptide 23, 24, ${ }^{18}$ or Boc-Gly-OH (25). Of particular note was the coupling of the amine derived from 16 and the dipeptide 23, where extensive racemization occurred to give predominantly the epimer 29 (22\% for $\mathbf{2 8}$ vs. $66 \%$ for 29). Deprotection of $\mathbf{2 9}$ gave 31, the diastereomer at the L-m-Tyr residue of $\mathbf{3 0}$.

The inhibitory activity of the analogues 2, 19, 27a-c, 30, and 31 on the purified MraY enzyme (Staphylococcus aureus) was next examined by fluorescence based MraY assay using UDP-MurNAc-dansylpentapeptide, where the formation of dansylated lipid I was monitored by fluorescence enhancement (excitation at $355 \mathrm{~nm}$, emission at $535 \mathrm{~nm}$ ), ${ }^{19}$ and the results are summarized in Table 1. It turned out that the epimer 19 was much 
weaker than the MraY inhibitors 1 or 2 with an $\mathrm{IC}_{50}$ value of $4000 \mathrm{nM}$. The stereochemistry at the DABA residue was very important for enzyme inhibitory activity. This was also true for the analogues $\mathbf{3 0}$ and 31, which possess the same stereochemistry at the DABA residue ( $\mathrm{IC}_{50} 650$ and $8900 \mathrm{nM}$, respectively). Analogue 27a showed similar inhibitory activity ( $\mathrm{IC}_{50} 22 \mathrm{nM}$ ) to that of $\mathbf{1}$ and $\mathbf{2}$, and introducing the Gly-L-m-Tyr moiety at the $N$-terminus did not improve but instead retained the activity. However, moving the hydroxyl group to the para-position at the $N$-terminal phenyl ring resulted in a large decrease in inhibitory activity with an $\mathrm{IC}_{50}$ value of $4000 \mathrm{nM}$ for $27 \mathbf{b}$. Therefore the position of the hydroxyl group on the phenyl ring plays a crucial role. Analogue 27c showed a slight decrease in MraY inhibitory activity. The antibacterial activity of 2, 19, 27a-c, 30, and 31 was then evaluated against a range of clinically isolated $P$. aeruginosa strains (Table 2). ${ }^{20}$ The overall antibacterial activity was well correlated to the MraY inhibitory activity. Thus, 27a showed a similar anti-Pseudomonal activity to that of 1 and 2, whereas 19, 27b, 27c, 30, and 31 exhibited no activity up to $32 \mu \mathrm{g} / \mathrm{mL}$. The exception was the Gly analogue 27c, which showed no anti-Pseudomonal activity in spite of potent MraY inhibitory activity (Table 1, IC $\mathrm{IC}_{50} 65$ $\mathrm{nM})$. 
In summary, the second-generation synthesis of $\mathbf{2}$ has been accomplished via a $\mathrm{U}-4 \mathrm{CR}$ at a late stage of the synthesis. This approach provided ready access to a range of analogues including the diastereomers of the DABA residue and hybrid-type analogues of the mureidomycins. Biological evaluations of these analogues indicated that the stereochemistry at the DABA residue has a significant impact on both the MraY biochemical inhibition and whole-cell antibacterial activity.

\section{References}

1. a) Karwowski, J. P.; Jackson, M.; Theriault, R. J.; Chen, R. H.; Barlow. G. J.; Maus, M. L. J. Antibiot. 1989, 42, 506. b) Chen, R. H.; Buko, A. M.; Whittern, D. N.; McAlpine, J. B. J. Antibiot. 1989, 42, 512. c) Fernandes, P. B.; Swanson, R. N.; Hardy, D. J.; Hanson, C. W.; Coen, L.; Rasmussen, R. R.; Chen, R. H. J. Antibiot. 1989, 42, 521. d) Fronko, R. M.; Lee, J. C.; Galazzo, J. G.; Chamberland, S.; Malouin, F.; Lee, M. D. J. Antibiot. 2000, 53, 1405.

2. a) Winn, M.; Goss, R. J. M.; Kimura, K.-I.; Bugg, T. D. H. Nat. Prod. Rep. 2010, 27, 279. b) Bugg, T. D. H.; Lloyd, A. J.; Roper, D. I. Infect. Dis. Drug Targets 2006, 6, 85. c) Kimura, K.-I.; Bugg, T. D. H. Nat. Prod. Rep. 2003, 20, 252.

3. a) Inukai, M.; Isono, F.; Takahashi, R.; Enokita, S.; Sakaida Y.; Haneishi, T. J. Antibiot. 1989, 42, 662. b) Isono, F.; Katayama, T.; Inukai, M.; Haneishi, T. J. 
Antibiot. 1989, 42, 674. c) Isono, F.; Inukai, M.; Takahashi, S.; Haneishi, T.;

Kinoshita, T.; Kuwano, H. J. Antibiot. 1989, 42, 667. d) Isono, F.; Sakaida, Y.;

Takahashi, S.; Kinoshita, T.; Nakamura, T.; Inukai, M. J. Antibiot. 1993, 46, 1203.

4. Chaterjee, S.; Nadkami, S. R.; Vijayakumar, E. K. S.; Patel, M. V.; Ganguli, B. N. J. Antibiot. 1994, 47, 595.

5. a) Xie, X. Y.; Chen, R. X.; Si, S. Y.; Sun, C. H.; Xu, H. Z. J. Antibiot. 2007, 60, 158.

b) Xie, X. Y.; Xu, H. Z.; Si, S. Y.; Sun, C. H.; Chen, R. X. J. Antibiot. 2008, 61, 237.

6. Tam, V. H.; Chang, K. T.; Abdelraouf, K.; Brioso, C. G.; Ameka, M.; McCaskey, L. A.; Weston, J. S.; Caeiro, J. P.; and Garey, K. W. Antimicrob. Agents Chemother. 2010, 54, 1160 .

7. Page, M. G.; Heim, J. Curr. Opin. Pharmacol. 2009, 9, 558.

8. Scheld, M.; Spellberg, B.; Bartlett, J. Clin. Infect. Dis. 2009, 48, 1.

9. a) Isono, F.; Inukai, M. Antimicrob. Agents Chemother. 1991, 35, 234. b) Inukai, M.; Isono, F.; Takatsuki, A. Antimicrob. Agents Chemother. 1993, 37, 980.

10. a) Bouhss, A.; Mengin-Lecreulx, D.; Le Beller, D.; Van Heijenoort, J. Mol. Microbiol. 1999, 34. 576. b) Bouhss, A.; Trunkfield, A. E.; Bugg, T. D.; Mengin-Lecreulx, D. FEMS Microbiol. Rev. 2008, 32, 208. c) Al-Dabbagh, B.; 
Henry, X.; El Ghachi, M.; Auger, G.; Blanot, D.; Parquet, C.; Mengin-Lecreulx, D.; Bouhss, A. Biochemistry 2008, 47, 8919.

11. a) Boojamra, C. G.; Lemoine, R. C.; Lee, J. C.; Léger, R.; Stein, K. A.; Vernier, N. G.; Magon, A.; Lomovskaya, O.; Martin, P. K.; Chamberland, S.; Lee, M. D.; Hecker, S. J.; Lee, V. J. J. Am. Chem. Soc. 2001, 123, 870. b) Lemoine, R. C.; Magon, A.; Hecker, S. Bioorg. Med. Chem. Lett. 2002, 12, 1121. c) Boojamra, C. G.; Lemoine, R. C.; Blais, J.; Vernier, N. G.; Stein, K. A.; Magon, A.; Chamberland, S.; Hecker, S. J.; Lee, V. J. Bioorg. Med. Chem. Lett. 2003, 13, 3305.

12. Gruschow, S.; Rackham, E. J.; Elkins, B.; Newill, P.; Hill, L. M.; Goss, R. J. M. ChemBioChem 2009, 10, 355.

13. a) Gentle, C. A.; Harrison, S. A.; Inukai, M.; Bugg, T. D. H. J. Chem. Soc. Perkin Trans. 1 1999, 1287. b) Howard, N. I.; Bugg, T. D. H. Bioorg. Med. Chem. 2003, 11, 3083.

14. Bozzoli, A.; Kazmierski, W.; Kennedy, G.; Pasquarello, A.; Pecunioso, A. Bioorg. Med. Chem. Lett. 2000, 10, 2759.

15. Sun, D. Q.; Jones, V.; Carson, E. I.; Lee, R. E. B.; Scherman, M. S.; McNeil, M. R.; Lee, R. E. Bioorg. Med. Chem. Lett. 2007, 17, 6899. 
16. a) Okamoto, K.; Sakagami, M.; Feng, F.; Togame, H.; Takemoto, H.; Ichikawa, S.; Matsuda A. J. Org. Chem. 2012, 77, 1367. b) Okamoto, K.; Sakagami, M.; Feng, F.; Togame, H.; Takemoto, H.; Ichikawa, S.; Matsuda A. Org. Lett. 2011, 13, 5240.

17. a) Tanino, T.; Al-Dabbagh, B.; Mengin-Lecreulx, D.; Bouhss, A.; Oyama, H.; Ichikawa, S.; Matsuda, A. J. Med. Chem. 2011, 54, 8421. b) Tanino, T.; Ichikawa, S.; Al-Dabbagh, B.; Bouhss, A.; Matsuda, A. ACS Med. Chem. Lett. 2010, 1, 258. c) Tanino, T.; Ichikawa, S.; Shiro, M.; Matsuda, A. J. Org. Chem. 2010, 75, 1366.

18. The dipeptides 23 and 24 were prepared by peptide coupling of either L-Tyr-OBn or L-m-Tyr-OBn with 25, protection of the phenol with the TBS group, and hydrogenolysis of the Bn group.

19. a) Bouhss, A.; Crouvoisier, M.; Blanot, D.; Mengin-Lecreulx D. J. Biol. Chem. 2004, 279, 29974. b) Ahmed, A.; Bararia, D.; Vinayak, S.; Yameen, M.; Biswas, S.; Dev, V.; Kumar, A.; Ansari, M. A.; Sharma, Y. D. Antimicrob. Agents Chemother. 2004, 48, 879 .

20. Maki, H.; Miura, K.; Yamano, Y. Antimicrob. Agents Chemother. 2001, 45, 1823. 


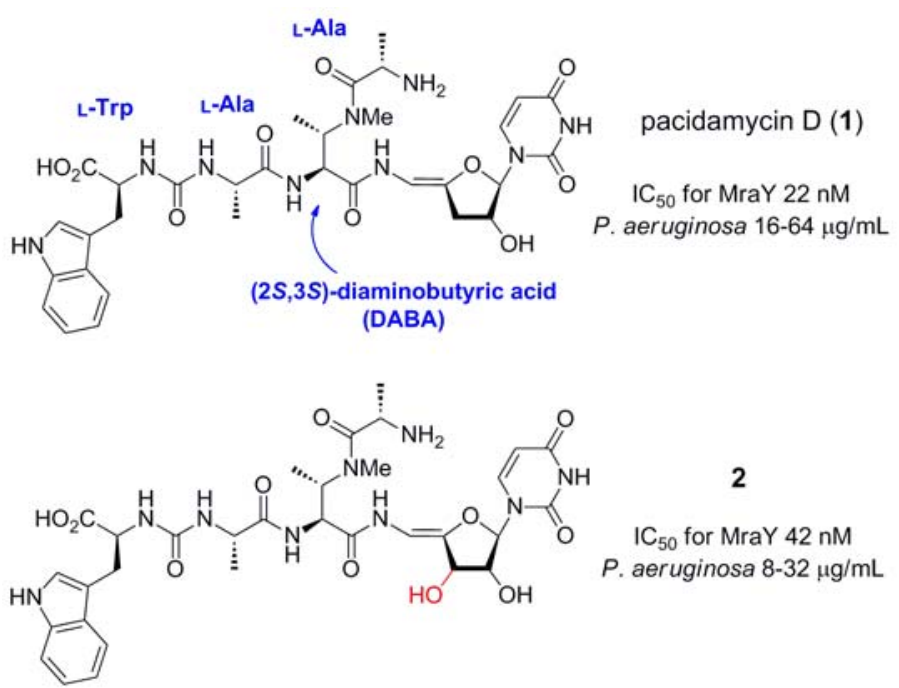

Figure 1. Structure of Pacidamycin D and Its 3'-Hydroxy analogue 2 


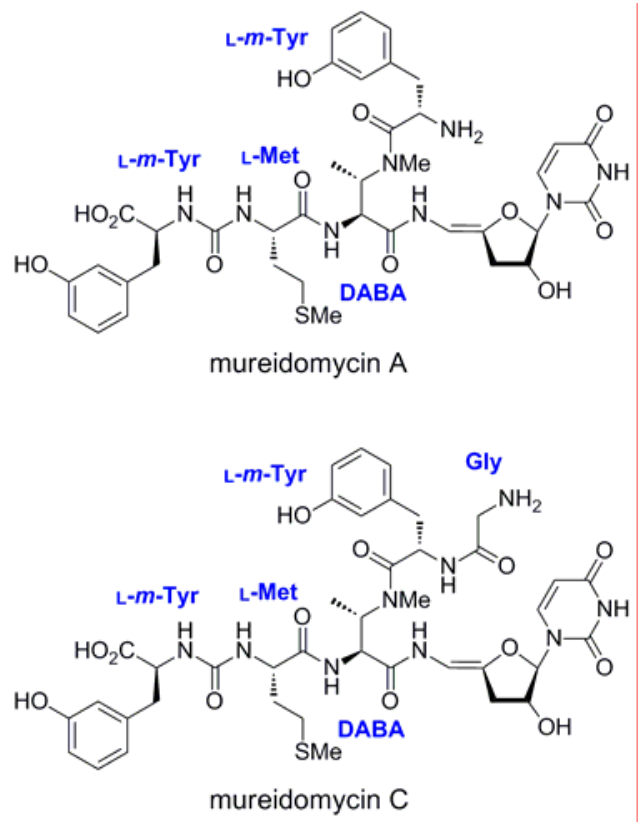

Figure 2. Structure of Mureidomycins 
Scheme 1. Retrosynthetic Analysis of 2 Disconnected by Ugi-Four Component Reaction
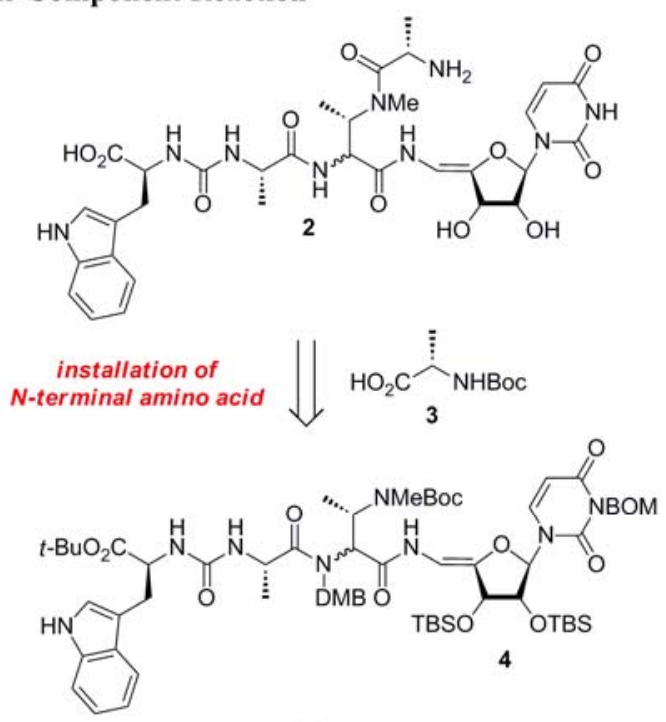

$\underset{(U-4 C R)}{U \text { gi-four component reaction }} \| \mathrm{DMB}=2,4$-dimethoxybenzyl

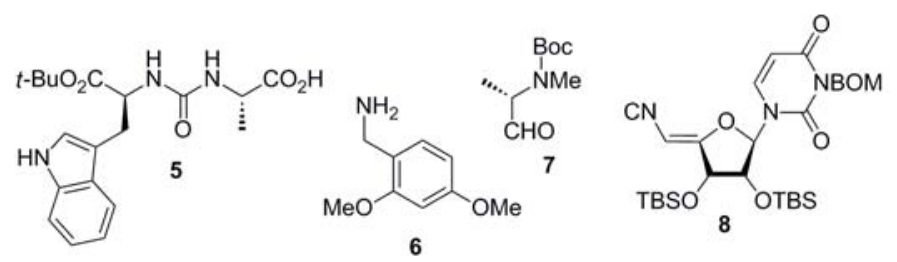


Scheme 2. Preparation of Aldehyde Unit 7

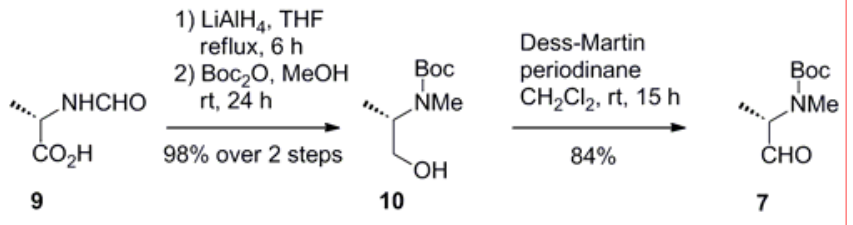


Scheme 3. Preparation of Isonitrile Unit 8

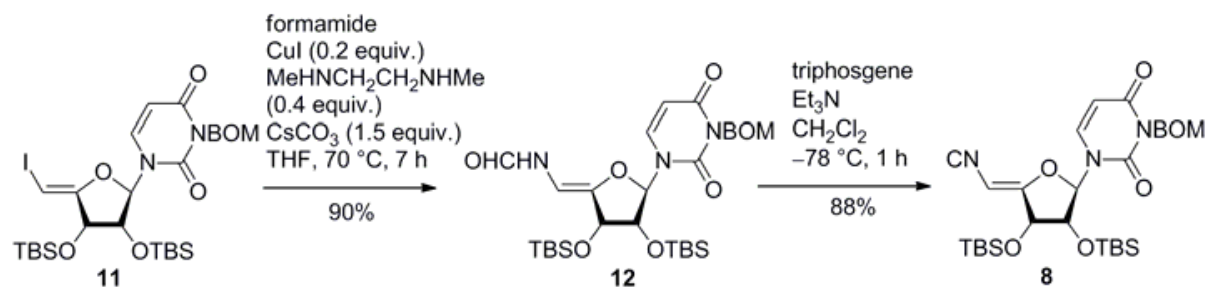


Scheme 4. Total Synthesis of 3'-Hydroxypacidamycin D (2) and Its Epimer 19
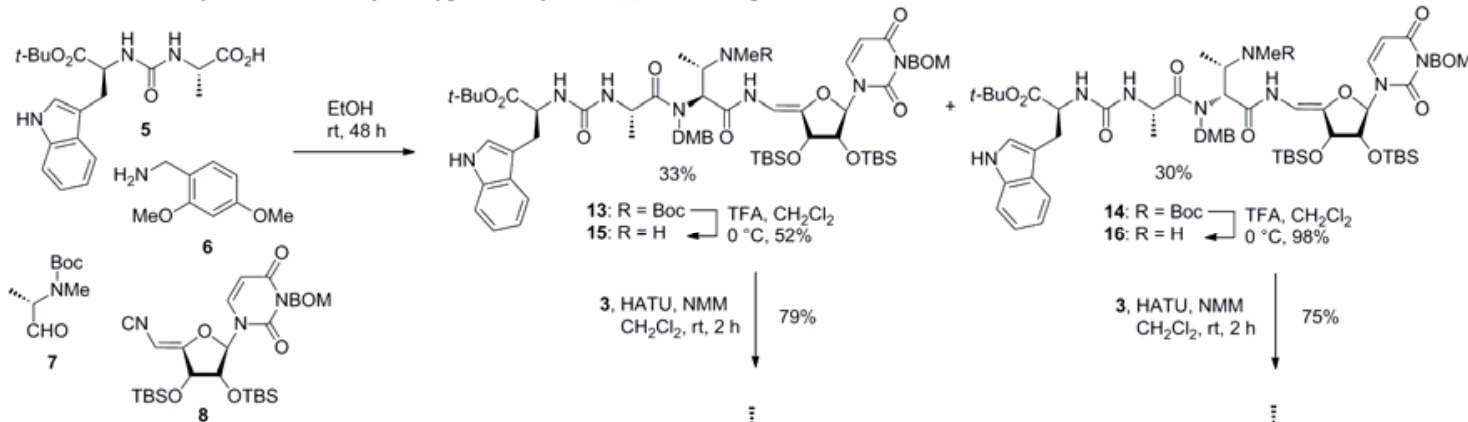

15: $\mathrm{R}=\mathrm{H}-0^{\circ} \mathrm{C}, \mathrm{CH}_{2} \%$

14: $\mathrm{R}=\mathrm{BOC} \rightarrow$ TFA, $\mathrm{CH}_{2} \mathrm{Cl}_{2}$

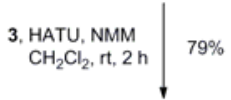

3. $\mathrm{HATU}, \mathrm{NMM}$
$\mathrm{CH}_{2} \mathrm{Cl}_{2}, \mathrm{rt}, 2 \mathrm{~h}$
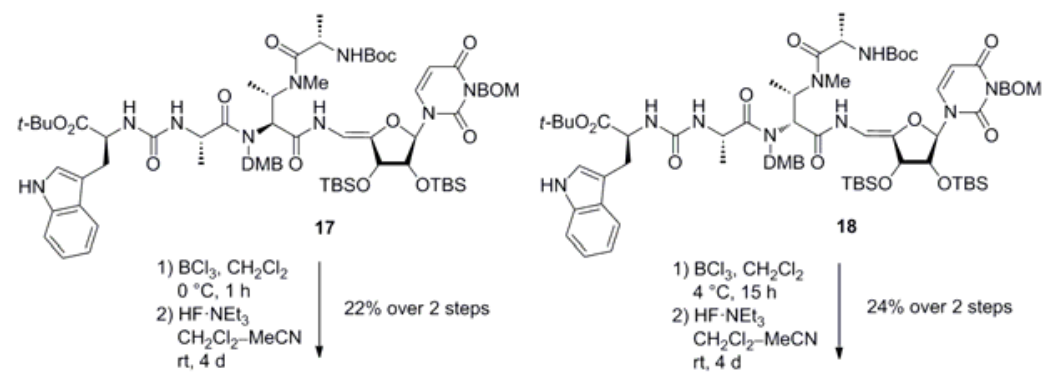

HATU: 2-(1H-7-azabenzotriazol1 -yl)-1,1,3,3-tetramethyl uronium hexafluorophosphate
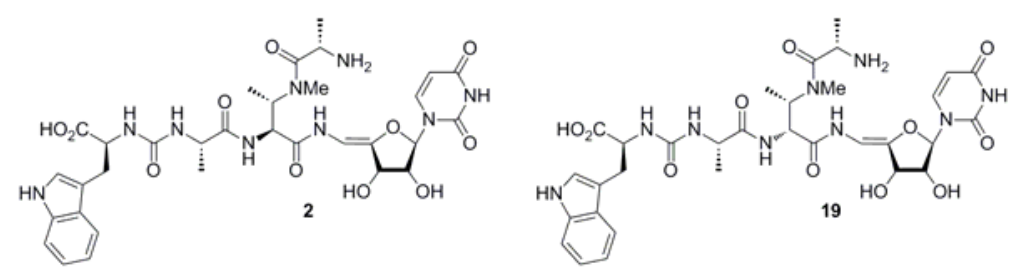
Scheme 5. Attempt to Use Dipeptide Aldehyde 21 in U-4CR

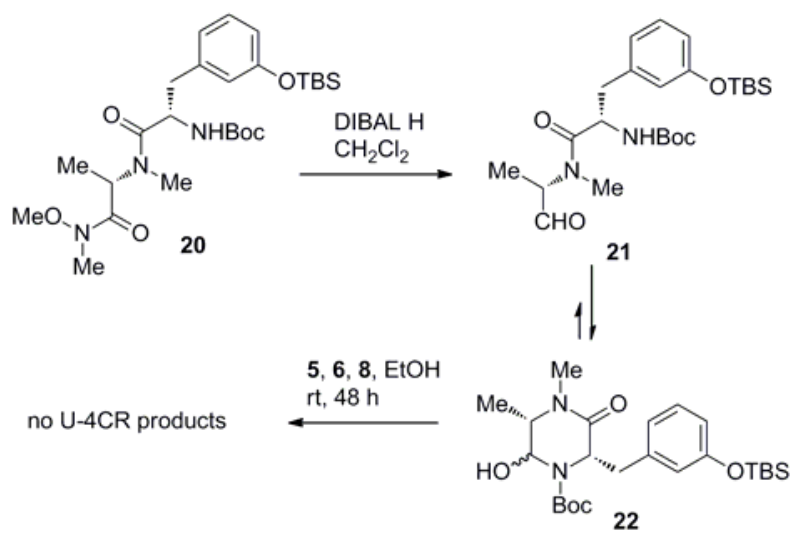


Scheme 6. Synthesis of Analogues 27a-c, 30 and 31

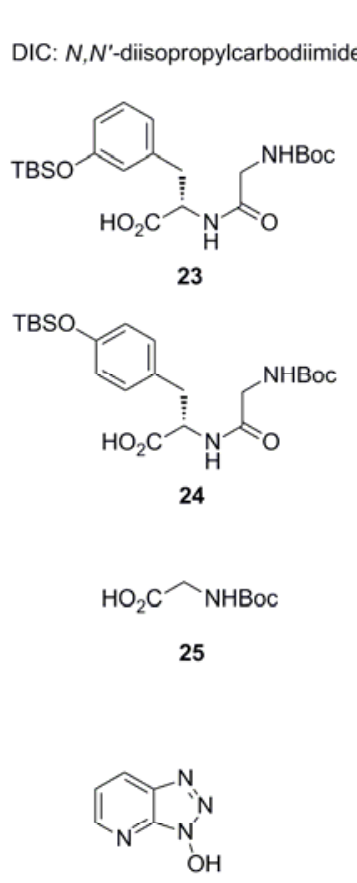

HOAt: 1H-7-azabenzotriazole

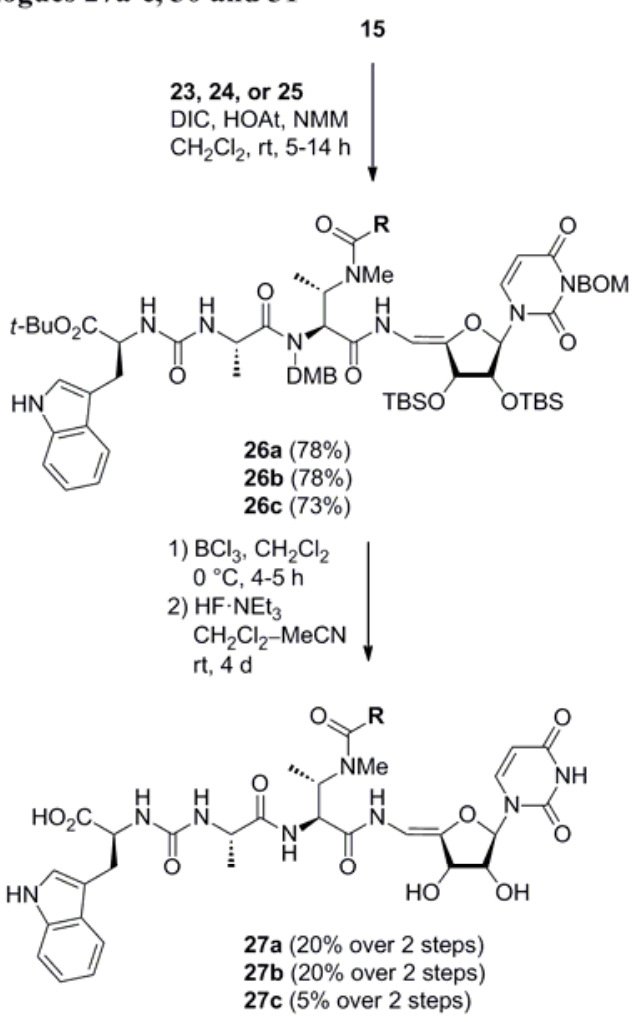

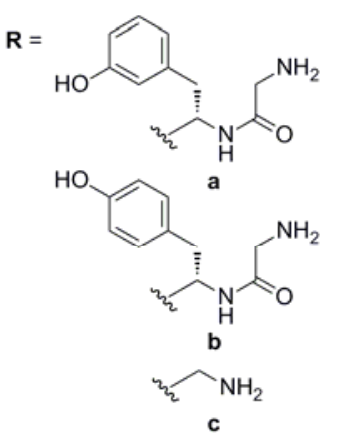

16
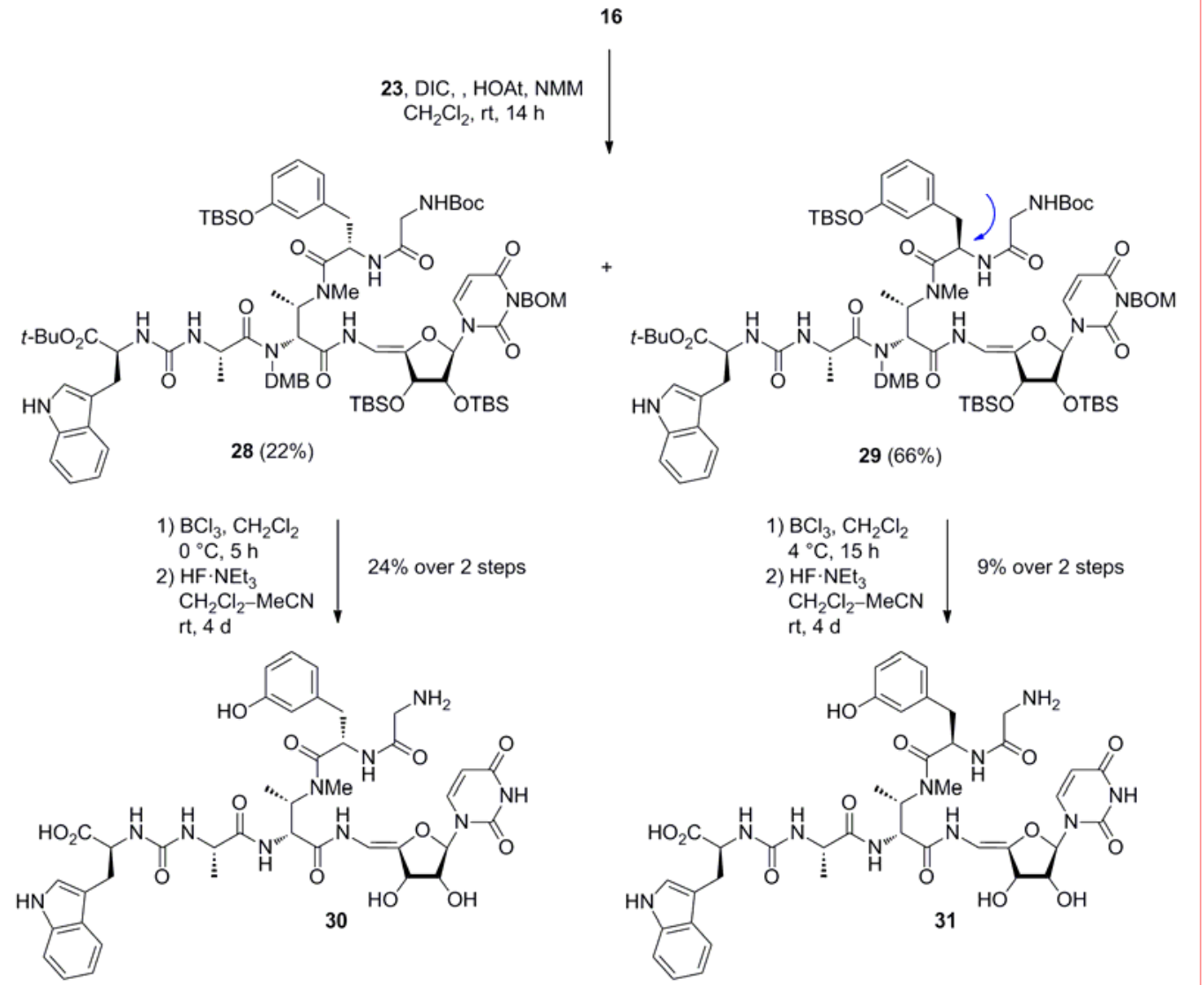
Table 1. MraY Inhibitory Activity of 3'-Hydroxypacidamycin Analogues

\begin{tabular}{ccccccccc}
\hline & $\mathbf{1}$ & $\mathbf{2}$ & $\mathbf{1 9}$ & $\mathbf{2 7 a}$ & $\mathbf{2 7 b}$ & $\mathbf{2 7 c}$ & $\mathbf{3 0}$ & $\mathbf{3 1}$ \\
\hline $\mathrm{IC}_{50}(\mathrm{nM})^{\mathrm{a}}$ & 22 & 42 & 4000 & 22 & 4000 & 65 & 650 & 8900
\end{tabular}

${ }^{a}$ The inhibitory activity of compounds on the purified MraY enzyme (Staphylococcus aureus) was then examined by fluorescence based MraY assay using UDP-MurNAcdansylpentapeptide, where the formation of dansylated lipid I was monitored by fluorescence enhancement (excitation at $355 \mathrm{~nm}$, emission at $535 \mathrm{~nm}$ ). 
Table 2. Anti-Pseudomonal Activity of 3'-Hydroxypacidamycin Analogues

\begin{tabular}{ccccc}
\hline & \multicolumn{4}{c}{ MIC $(\mu \mathrm{g} / \mathrm{mL})^{\mathrm{a}}$} \\
\cline { 2 - 5 } compound & $\begin{array}{c}\text { P. aeruginosa } \\
\text { PAO1 }\end{array}$ & $\begin{array}{c}\text { P. aeruginosa } \\
\text { YY165 }(\Delta \operatorname{mexB})\end{array}$ & $\begin{array}{c}\text { P. aeruginosa } \\
\text { ATCC } 25619\end{array}$ & $\begin{array}{c}\text { P. aeruginosa } \\
\text { SR 27156 }\end{array}$ \\
\hline $\mathbf{1}$ & 64 & 16 & 16 & 16 \\
$\mathbf{2}$ & 32 & 8 & 16 & 16 \\
$\mathbf{1 9}$ & $>32$ & $>32$ & $>32$ & $>32$ \\
$\mathbf{2 7 a}$ & $>32$ & 16 & 32 & 16 \\
$\mathbf{2 7 b}$ & $>32$ & $>32$ & $>32$ & $>32$ \\
$\mathbf{2 7 c}$ & $>32$ & $>32$ & $>32$ & $>32$ \\
$\mathbf{3 0}$ & $>32$ & $>32$ & $>32$ & $>32$ \\
$\mathbf{3 1}$ & $>32$ & $>32$ & $>32$ & $>32$ \\
\hline
\end{tabular}

${ }^{a}$ MICs were determined by a microdilution broth method as recommended by the NCCLS with cation-adjusted Mueller-Hinton broth (CA-MHB). Serial two-fold dilutions of each compound were made in appropriate broth, and the plates were inoculated with $5 \times 10^{4} \mathrm{CFU}$ of each strain in a volume of $0.1 \mathrm{~mL}$. Plates were incubated at $35^{\circ} \mathrm{C}$ for $20 \mathrm{~h}$ and then MICs were scored. 


\section{Captions}

Figure 1. Structure of Pacidamycin D and Its 3'-Hydroxy analogue 2

Figure 2. Structure of the Mureidomycins

Scheme 1. Retrosynthetic Analysis of 2 Disconnected by an Ugi-Four Component Reaction

Scheme 2. Preparation of the Aldehyde Unit 7

Scheme 3. Preparation of the Isonitrile Unit 8

Scheme 4. Total Synthesis of 3'-Hydroxypacidamycin D (2) and Its Epimer 19

Scheme 5. Attempt to Use the Dipeptide Aldehyde 21 in the U-4CR

Scheme 6. Synthesis of Analogues 27a-c, 30 and 31

Table 1. MraY Inhibitory Activity of 3'-Hydroxypacidamycin Analogues

Table 2. Anti-Pseudomonal Activity of 3'-Hydroxypacidamycin Analogues 